\title{
Risk factors, complications and survival after upper abdominal surgery: a prospective cohort study
}

\author{
E. K. Aahlin ${ }^{1,2^{*}}$, G. Tran $\varnothing^{3}$, N. Johns ${ }^{4}$, A. Horn ${ }^{5}$, J. A. Søreide ${ }^{6,7}$, K.C. Fearon ${ }^{4}$, A. Revhaug ${ }^{1,2}$ and K. Lassen ${ }^{1,2}$
}

\begin{abstract}
Background: Preoperative weight loss and abnormal serum-albumin have traditionally been associated with reduced survival. More recently, a correlation between postoperative complications and reduced long-term survival has been reported and the significance of the relative proportion of skeletal muscle, visceral and subcutaneous adipose tissue has been examined with conflicting results. We investigated how preoperative body composition and major non-fatal complications related to overall survival and compared this to established predictors in a large cohort undergoing upper abdominal surgery.
\end{abstract}

Methods: From 2001 to 2006, 447 patients were included in a Norwegian multicenter randomized controlled trial in major upper abdominal surgery. Patients were now, six years later, analyzed as a single prospective cohort and overall survival was retrieved from the National Population Registry. Body composition indices were calculated from $\mathrm{CT}$ images taken within three months preoperatively.

Results: Preoperative serum-albumin $<35 \mathrm{~g} / \mathrm{l}(\mathrm{HR}=1.52, \mathrm{p}=0.014)$ and weight loss $>5 \%(\mathrm{HR}=1.38, p=0.023)$ were independently associated with reduced survival. There was no association between any of the preoperative body composition indices and reduced survival.

Major postoperative complications were independently associated with reduced survival but only as long as patients who died within 90 days were included in the analysis.

Conclusions: Our study has confirmed the robust significance of the traditional indicators, preoperative serum-albumin and weight loss. The body composition indices did not prove beneficial as global indicators of poor prognosis in upper abdominal surgery. We found no association between non-fatal postoperative complications and long-term survival.

Keywords: Sarcopenia, Cachexia, Cancer, Gastrointestinal, Hepatopancreatobiliary, Surgery

\section{Background}

Preoperative weight loss and abnormal serum-albumin have been associated with unfavorable postoperative outcome for more than a decade [1-3]. An involuntary weight loss of five percent or more has been recognized to be associated with reduced survival for more than thirty years and it has been proposed as a diagnostic criterion for cancer cachexia [4-6].

\footnotetext{
* Correspondence: eirik.kjus.aahlin@unn.no

'Department of Gl and HPB Surgery, University Hospital of Northern Norway, Tromsø 9038, Breivika, Norway

${ }^{2}$ Institute of Clinical Medicine, University of Troms $\varnothing$ - The Arctic University of Norway, Tromsø, Norway

Full list of author information is available at the end of the article
}

Sarcopenia (i.e. loss of skeletal muscle) has been shown to be associated with reduced survival after cancer surgery [7-9]. Sarcopenia has also been associated with postoperative complications [10], increased chemotherapy toxicity and decreased time to tumor progression [11]. While visceral adiposity has been associated with diabetes, and diabetes again has been associated with unfavorable outcome after surgery; evaluations of a direct association between adipose tissue indices and unfavorable outcome have shown conflicting results $[9,12,13]$.

An association between major postoperative complications and reduced long-term survival has been shown for a wide range of malignant and non-malignant diseases [14-19]. Khuri et al. reported such association 
even when those who die within 30 days after surgery were excluded from analysis and it has been suggested that complications could alter the immune system and make patients more susceptible to cancer recurrence $[14,15]$. In light of improved, modern intensive care medicine we suspect that a 30 day cut-off might not correctly identify those who die as a direct result of their complication. It is not known whether there is an association between complications and long-term survival in major upper abdominal surgery when only those who survive more than 90 days after surgery are analyzed.

We aimed to investigate the association between preoperative body composition indices, weight loss and serum-albumin, postoperative complications and overall survival after major upper abdominal surgery.

\section{Methods}

From 2001 to 2006, 447 patients were included in a Norwegian multicenter randomized controlled trial (RCT), which investigated normal food at will after major upper gastrointestinal (GI) and hepatopancreatobiliary (HPB) surgery [20]. Further analysis has not been performed on this dataset and it was treated here as a single, prospective cohort. We retrieved survival data from the Norwegian Population Registry during April 2012, six years after the last patient was included in the original trial.

In addition to demographics and general clinical characteristics, the prospective database included specifically: patient-reported preoperative weight loss, preoperative serum-albumin, type of surgery and major postoperative complications. Major complications, within eight weeks after surgery where defined a priori in the original trial [20] (Table 1). The operative procedures were listed in the original publication [20].

Preoperative weight loss was calculated from patients' usual pre-morbid weight as they reported it - with no time limit, and current weight as scaled preoperatively at trial enrolment. We used well-established cut-offs for preoperative weight loss and serum-albumin $[6,21]$. Preoperative weight loss was dichotomized into $>5 \%$ or $\leq 5 \%$. Preoperative serum-albumin was dichotomized into $<35.0 \mathrm{~g} / \mathrm{l}$ or $\geq 35.0 \mathrm{~g} / \mathrm{l}$. Body Mass Index, BMI was calculated with the following formula [22]: $\mathrm{BMI}=$ weight $(\mathrm{kg}) /$ height $^{2}(\mathrm{~m})$.

Digitally stored computer tomography (CT) images for initial routine diagnostics and staging were analyzed using Slice-O-Matic software V4.2 (Tomovision, MontrealCanada) which permitted specific tissue demarcation using Houndsfield unit threshold of -29 to +150 for skeletal muscles [23], -150 to -50 for visceral adipose tissue [24], and -190 to -30 for subcutaneous adipose tissue [23]. Cross-sectional areas $\left(\mathrm{cm}^{2}\right)$ were calculated for each tissue by summing tissue pixels and multiplying by the pixel surface area. A transverse CT image from the third lumbar vertebrae (L3) was assessed for each scan and tissue areas estimated [25]. All CT images were analyzed by one single trained observer who was blinded to all clinical data. Cross-sectional area was normalized for stature $\left(\mathrm{cm}^{2} / \mathrm{m}^{2}\right)$ and the following indices were calculated: L3 Skeletal muscle index (L3 SMI), L3 Visceral adipose tissue index (L3 VAT) and L3 Subcutaneous adipose tissue index (L3 SAT). CT images used for analysis were retrieved from routine images done within three months preoperatively.

We used the cut-off for L3 SMI suggested by Martin et al. [26]: L3 SMI $<41 \mathrm{~cm}^{2} / \mathrm{m}^{2}$ for women, L3 SMI $<43 \mathrm{~cm}^{2} / \mathrm{m}^{2}$ for men with BMI $<25 \mathrm{~kg} / \mathrm{m}^{2}$ and L3 SMI $<53 \mathrm{~cm}^{2} / \mathrm{m}^{2}$ for men with BMI $\geq 25 \mathrm{~kg} / \mathrm{m}^{2}$. We also calculated the percentage of women and men with L3 SMI lower than the cut-offs suggested by Mourtzakis et al. and later used in a consensus article on cachexia and sarcopenia [6, 27], which corresponds to skeletal muscle mass two standard deviations from that of healthy young adults $\left(39 \mathrm{~cm}^{2} / \mathrm{m}^{2}\right.$ for women and $55 \mathrm{~cm}^{2} / \mathrm{m}^{2}$ for men). Preoperative weight loss, serum-albumin and L3 SMI were analyzed both as dichotomous and continuous variables. L3 VAT and L3 SAT were analyzed only as continuous variables.

All patients with complete data sets for preoperative serum-albumin and weight loss were included in analysis. A subgroup analysis was performed on patients with available preoperative CT images. Patients were divided into the following disease-categories: Gastroesophageal cancer, pancreatic cancer, other cancer (mainly malignant liver tumors and colorectal liver metastasis) and non-cancer.

\section{Statistics}

Statistical analysis was performed with SPSS statistics software, version 22 (IBM, New York -USA). A Cox proportional hazard regression analysis, stratified for disease-categories, was used for analysis of overall survival; the assumption of proportional hazards was visually inspected by log-log survival curves. For comparison of characteristics between different groups and categories, analysis of variance (ANOVA) for continuous data and Pearson chi-square test for categorical data were used. Kruskal-Wallis test and Mann-Whitney $U$ test were used for non-normally distributed data. P-values $<0.05$ were considered statistically significant.

\section{Results}

\section{Selection and characteristics}

There were 447 patients included in the original trial. Survival data were obtained for 438 patients (98.0\%). Complete information on preoperative weight loss and serum-albumin was available for 369 patients (82.5\%). Preoperative CT images of sufficient quality were available in 157 of these patients $(157 / 369=42.5 \%)$. There 
Table 1 Major postoperative complications: definition and criteria

\begin{tabular}{|c|c|}
\hline Complication & Criteria \\
\hline \multirow[t]{6}{*}{ SIRS } & Two or more of the following: \\
\hline & Temperature $>38^{\circ} \mathrm{C}$ or $<36^{\circ} \mathrm{C}$ \\
\hline & Heart rate $>90$ beats $/ \mathrm{min}$ \\
\hline & Respiratory rate $>20 / \mathrm{min}$ or $\mathrm{PaCO} 2<4,3 \mathrm{kPa}$ \\
\hline & White blood cell count $>12000 \mathrm{cell} / \mathrm{ml}$ or \\
\hline & $<4000$ cells $/ \mathrm{ml}$ or $>10 \%$ immature forms \\
\hline Bacteraemia & At least one positive blood culture of pathogenic organisms \\
\hline Sepsis & SIRS + bacteraemia \\
\hline Pneumonia & X-ray confirmed and necessitating antibiotic treatment \\
\hline Anastomotic leak & Necessitating re-operation or demonstrated upon autopsy \\
\hline Bowel obstruction, necrosis or perforation & Necessitating re-operation or demonstrated upon autopsy \\
\hline Intra abdominal abscess & Necessitating re-operation or percutaneous drainage or demonstrated upon autopsy \\
\hline Intra abdominal haemorrhage & $\begin{array}{l}\text { Necessitating re-operation, transfusion of six or more units of Packed Red Blood Cells within } \\
\text { first } 48 \mathrm{~h} \text { postop. or demonstrated upon autopsy }\end{array}$ \\
\hline Wound rupture & Necessitating re-suturing in general anesthesia or demonstrated upon autopsy \\
\hline Pancreatitis & $\begin{array}{l}\text { Serum enzyme level twice upper normal value, absence of known pre-existing pancreatitis, ERCP or } \\
\text { mechanical trauma to pancreas during operation providing satisfactory explanation for elevated enzymes }\end{array}$ \\
\hline Cholecystitis & Confirmed by histological examination of specimen or by cultured content from percutaneous drainage \\
\hline Myocardial infarction & Diagnostic enzyme pattern and either typical pain or ECG changes, or demonstrated upon autopsy \\
\hline Myocardial arrhythmia & ECG confirmed, with hypotension or symptomatic angina, necessitating stabilizing drugs or electro-conversion \\
\hline Cardiac arrest & Confirmed by ECG or cardiac rhythm monitoring, and necessitating resuscitation \\
\hline Acute Cardiac failure & Confirmed by by Echocardiosonography or necessitating pressure agents \\
\hline $\begin{array}{l}\text { Cerebrovascular infarction or } \\
\text { cerebrovascular haemorrhage }\end{array}$ & New, and persistent ( $>48$ h) central neurological deficit, and confirmed by $\subset T$ scan or demonstrated upon autopsy \\
\hline Pulmonary embolism & $\begin{array}{l}\text { Confirmed by unequivocal nuclear isotope scan, ECG, pulmonary angiography, spiral technique CT scan } \\
\text { or demonstrated upon autopsy }\end{array}$ \\
\hline Pulmonary insufficiency & Necessitating postoperative ventilation support more than $24 \mathrm{~h}$ \\
\hline
\end{tabular}

Major postoperative complications as defined in the original randomized trial [20]

were no significant differences in complication rates or overall survival between patients included $(n=369)$ and those excluded due to missing nutritional data $(n=69)$. There were no significant differences in complication rates or overall survival between patients with available CT images $(n=157)$ and patients without available CT images $(n=212)$. Of the 369 patients available for analysis, 26 patients $(7.0 \%)$ had died within 90 days. The five year mortality rates varied between $20.4 \%$ in patients without cancer and $77.6 \%$ in patients with pancreatic cancer (Table 2).

\section{Preoperative weight loss, serum-albumin and body composition}

Median preoperative weight loss was $1.8 \%$ (not normally distributed). There were 131 patients with preoperative weight loss $>5 \%(35.6 \%)$ while 175 patients had no preoperative weight loss (47.4\%). Mean serum- albumin concentration was $39.0 \mathrm{~g} / \mathrm{l}$. The number of patients with serum-albumin $<35 \mathrm{~g} / \mathrm{l}$ was $62(16.8 \%)$.

Five-year mortality spanned from $44.6 \%$ in patients with no preoperative weight loss to $67.8 \%$ in patients with $>10 \%$ preoperative weight loss (Table 3). There were no statistically significant differences in L3 SMI between different preoperative weight loss categories (Table 3).

Mean L3 SMI was $41.8 \mathrm{~cm}^{2} / \mathrm{m}^{2}$ in women and $47.0 \mathrm{~cm}^{2} / \mathrm{m}^{2}$ in men. Of the 157 patients with L3 SMI analyzed, 72 (45.9\%) had L3 SMI below Martin's cut-off [26]. Only $7(9.7 \%)$ of these patients were obese. The proportion of women and men with L3 SMI below Martin's cut-off were $47.5 \%$ and $44.8 \%$ respectively.

The number of patients with L3 SMI below Mourtzakis's cut-off [27] was 110 (70.1\%). Only 6 (5.5\%) of these patients were obese. The proportion of women and men with L3 SMI below Mourtzakis's cut-off were $37.7 \%$ and $90.6 \%$ respectively (Fig. 1). 
Table 2 Disease categories: characteristics, postoperative complications and 5-year mortality

\begin{tabular}{|c|c|c|c|c|c|}
\hline & $\begin{array}{l}\text { Gastroesophageal cancer } \\
(n=122)\end{array}$ & $\begin{array}{l}\text { Pancreatic cancer } \\
(n=85)\end{array}$ & $\begin{array}{l}\text { Other cancer } \\
(n=64)\end{array}$ & $\begin{array}{l}\text { Non cancer } \\
(n=98)\end{array}$ & $\begin{array}{l}P- \\
\text { value }\end{array}$ \\
\hline Age, mean (SD) & $68(13)$ & $64(10)$ & $63(13)$ & $60(15)$ & $<0.001$ \\
\hline Male gender, n (\%) & 75 (61.4\%) & $58(68.2 \%)$ & $36(56.3 \%)$ & $50(51.0 \%)$ & 0.108 \\
\hline Complications ${ }^{a}, \mathrm{n}(\%)$ & 45 (36.9 \%) & 27 (31.8\%) & 21 (32.8 \%) & 22 (22.4\%) & 0.143 \\
\hline 5-year mortality, n (\%) & 79 (64.8\%) & 66 (77.6 \%) & 35 (54.7\%) & 20 (20.4\%) & $<0.001$ \\
\hline
\end{tabular}

a) Major postoperative complications within eight weeks after surgery

A significant difference in BMI and age by quartile categories of L3 SMI was observed (Table 4). However, no significant differences in complication rates or five-year mortality between the different quartile categories of L3 SMI were found, nor did we demonstrate any differences in mean preoperative weight loss or serum-albumin (Table 4).

\section{Complications}

Major postoperative complications were suffered by 115 (31.2 \%) patients. The only variable that differed significantly between patients with and without major postoperative complications was serum-albumin concentration $(p=0.016)$. Odds ratio for major postoperative complications with preoperative serum-albumin $<35 \mathrm{~g} / \mathrm{l}$ was 2.08 $(p=0.010)$. There were no significant association between preoperative weight loss and major postoperative complications $(p=0.688)$.

\section{Overall survival}

Preoperative weight loss $>5 \%(\mathrm{HR}=1.38, p=0.023)$ and preoperative serum-albumin $<35 \mathrm{~g} / \mathrm{l}(\mathrm{HR}=1.52, p=0$ .014) were independently associated with reduced overall survival (Table 5). Experiencing a major postoperative complication was independently associated with reduced overall survival $(\mathrm{HR}=1.51, p=0.003)$, but not when patients who died within 90 days after surgery were excluded from analysis $(p=0.133)$ (Table 5).

L3 SMI below Martin's cut-off values [26] were associated with statistically significant improved overall survival in the unadjusted analysis ( $\mathrm{HR}=0.66, p=0.037$ ), but this significance did not remain in the multivariable adjusted analysis $(\mathrm{HR}=0.69, p=0.066)$ (Table 5). Similar results were seen after exclusion of patients without cancer, in both the unadjusted $(\mathrm{HR}=0.60, p=0.014)$ and multivariable adjusted $(\mathrm{HR}=0.62, p=0.026)$ analysis.

There was no significant association between L3 SMI, L3 VAT or L3 SAT and changes in overall survival (Table 5). Preoperative weight loss and serum-albumin, when analyzed as continuous variables in the same subgroup, were independently associated with statistically significant changes in overall survival.

\section{Discussion}

The main aim of our investigation was to explore the novel field of CT-based preoperative body composition indices and compare with traditional indicators for poor prognosis and to explore the significance of non-fatal major postoperative complications. We have shown a significant association between both preoperative weight loss $>5 \%$ and serum-albumin $<35 \mathrm{~g} / \mathrm{l}$ and reduced overall survival in a large cohort of patients undergoing major upper abdominal surgery. Conversely, there was no association between L3 skeletal muscle index, L3 visceral adipose tissue index or L3 subcutaneous adipose tissue index, and overall survival. We found an association between major postoperative complications and reduced overall survival, but not when patients who died within 90 days after surgery were excluded from analysis.

The relationship between patient-reported preoperative weight loss and adverse outcome has been known since Hiram Studley's 1936 publication on mortality after surgery for chronic peptic ulcer patients [4]. The relationship between abnormal serum-albumin and adverse outcome is well documented [2,3]. Our study has again

Table 3 Categories of preoperative weight loss: characteristics, complications and 5-year mortality

\begin{tabular}{llllll}
\hline & $\begin{array}{l}\text { No weight loss } \\
(n=175)\end{array}$ & $\begin{array}{l}1-5 \% \text { weight loss } \\
(n=63)\end{array}$ & $\begin{array}{l}\text { 6-10\% weight loss } \\
(n=72)\end{array}$ & $\begin{array}{l}>10 \% \text { weight loss } \\
(n=59)\end{array}$ & $\begin{array}{l}P \text { - } \\
\text { value }\end{array}$ \\
\hline Serum-albumin (g/l), mean (SD) & $40.3(5.6)$ & $38.4(5.6)$ & $38.1(4.4)$ & $46.9(5.4)$ & $43.0(6.1)$ \\
L3 SMl, mean (SD) $^{\text {a }}$ & $45.6(7.3)$ & $43.1(5.5)$ & $46.6(5.6)$ & $18(30.5 \%)$ & 0.071 \\
Complications $^{b}$ & $51(29.1 \%)$ & $21(33.3 \%)$ & $25(34.7 \%)$ & $40(67.8 \%)$ & 0.823 \\
5-year mortality, n (\%) & $78(44.6 \%)$ & $37(58.7 \%)$ & $45(62.5 \%)$ & 0.004 \\
\hline
\end{tabular}

a) Calculated for patients with available preoperative CT images only $(n=157)$

b) Major postoperative complications within eight weeks after surgery 


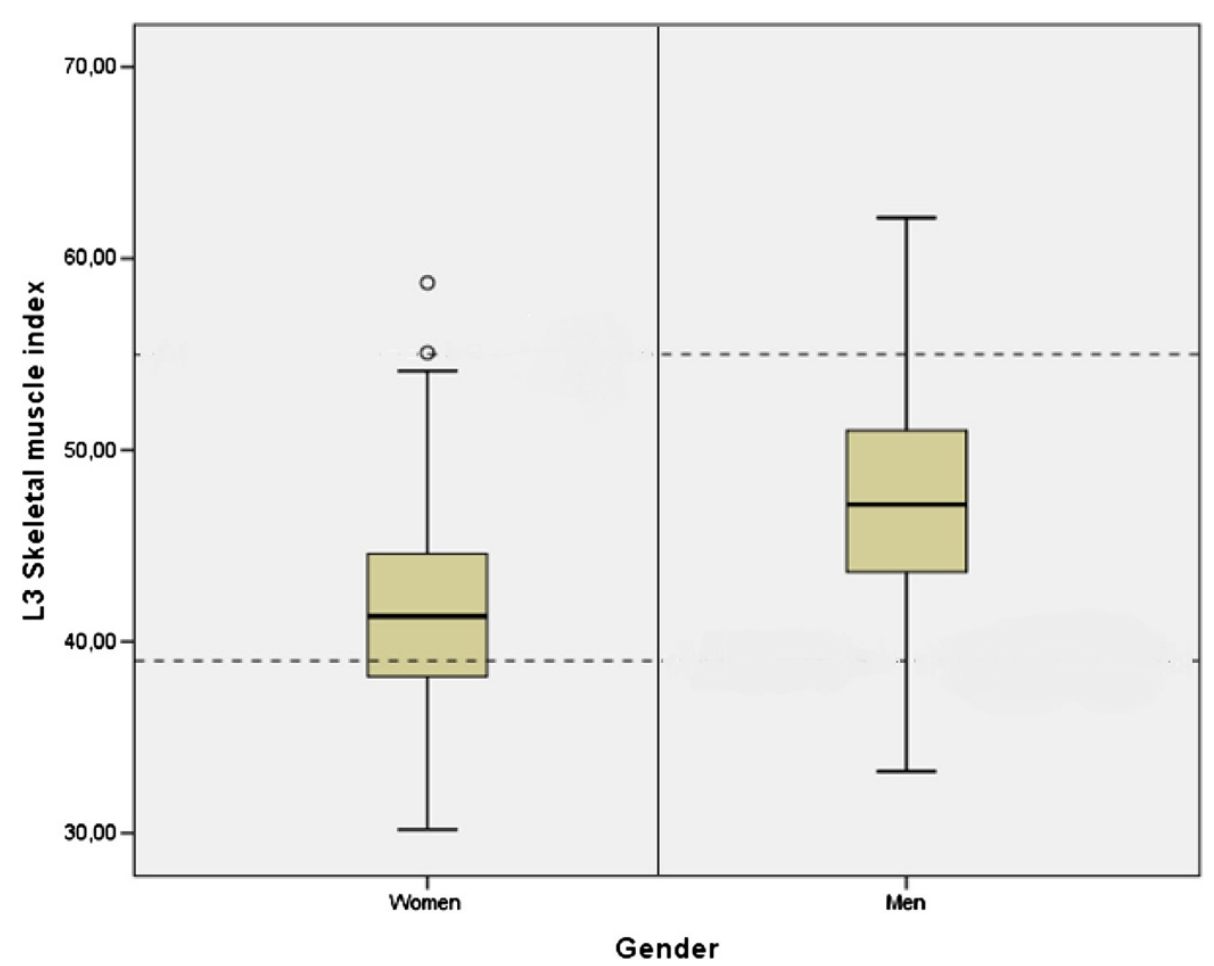

Fig. 1 Distribution of $L 3$ skeletal muscle index

confirmed the robust significance of these easily available indicators.

CT-based body composition indices constitute a novel field. Two methods for calculating skeletal muscle area have emerged in the recent years: the measurement of the total psoas muscle area and the combined skeletal muscle area on a transverse CT image at the third lumbar vertebrae level [27, 28]. Several different cut-off values for L3 skeletal muscle index (L3 SMI) to define sarcopenia have been suggested, some of them are almost identical. Mourtzakis et al. suggested cut-offs, corresponding to skeletal muscle mass as measured on dual energy $\mathrm{x}$-ray absorptiometry, to be two standard deviations below that of healthy young adults [27]. These cut-offs, $39 \mathrm{~cm}^{2} / \mathrm{m}^{2}$ for women and $55 \mathrm{~cm}^{2} / \mathrm{m}^{2}$ for men, were later used in a consensus document on cancer cachexia [6]. Prado et al. suggested cut-offs in sarcopenicobese patients at $38.5 \mathrm{~cm}^{2} / \mathrm{m}^{2}$ for women and $52.4 \mathrm{~cm}^{2} /$ $\mathrm{m}^{2}$ for men [29]. Van Vledder et al. suggested cut-offs in patients with colorectal liver metastasis: $41.1 \mathrm{~cm}^{2} / \mathrm{m}^{2}$ for women and $43.75 \mathrm{~cm}^{2} / \mathrm{m}^{2}$ for men [8]. Based on a large cohort of patients with gastrointestinal and lung cancers, Martin et al. developed cut-offs according to Body Mass Index [26]: $41 \mathrm{~cm}^{2} / \mathrm{m}^{2}$ for women, $43 \mathrm{~cm}^{2} / \mathrm{m}^{2}$ and $53 \mathrm{~cm}^{2} / \mathrm{m}^{2}$ for men with BMI under or over $25 \mathrm{~kg} / \mathrm{m}^{2}$ respectively.

Table 4 Quartile categories of L3 Skeletal muscle index: characteristics, complications and 5-year mortality

\begin{tabular}{|c|c|c|c|c|c|}
\hline & 1. quartile $(n=39)$ & 2. quartile $(n=39)$ & 3. quartile $(n=36)$ & 4. quartile $(n=43)$ & \multirow{3}{*}{$\begin{array}{l}P \text { - } \\
\text { value }\end{array}$} \\
\hline & $\begin{array}{l}\text { Range L3 SMl } \\
\left(\mathrm{cm}^{2} / \mathrm{m}^{2}\right)=\mathrm{W}: 30.2-38.1\end{array}$ & $\begin{array}{l}\text { Range L3 SMl } \\
\left(\mathrm{cm}^{2} / \mathrm{m}^{2}\right)=W: 38.2-41.1\end{array}$ & $\begin{array}{l}\text { Range L3 SMl } \\
\left(\mathrm{cm}^{2} / \mathrm{m}^{2}\right)=W: 41.3-44.5\end{array}$ & $\begin{array}{l}\text { Range L3 SMl } \\
\left(\mathrm{cm}^{2} / \mathrm{m}^{2}\right)=W: 45.6-58.7\end{array}$ & \\
\hline & M: $33.2-43.5$ & M: 43.7-47.0 & M: 47.3-50.1 & M: 50.2-62.2 & \\
\hline Age, mean (SD) & $67(12)$ & $65(11)$ & $59(12)$ & $62(12)$ & 0.024 \\
\hline BMI $\left(\mathrm{kg} / \mathrm{m}^{2}\right)$, mean $(\mathrm{SD})$ & $22.9(3.5)$ & $24.2(3.7)$ & $24.9(3.9)$ & $27.7(4.8)$ & $<0.001$ \\
\hline Weight loss (\%), mean (SD) & $6.0(6.6)$ & $5.2(6.2)$ & $5.2(6.4)$ & $2.7(5.0)$ & 0.001 \\
\hline Serum-albumin $(g / l)$, mean (SD) & $39.9(7.4)$ & $39.0(4.0)$ & $39.8(7.1)$ & $39.5(5.2)$ & 0.911 \\
\hline Complications $^{\mathrm{a}}$, n (\%) & $12(30.8 \%)$ & $18(46.2 \%)$ & $12(33.3 \%)$ & $12(27.9 \%)$ & 0.329 \\
\hline 5-year mortality, n (\%) & $22(56.4 \%)$ & $25(64.1 \%)$ & $25(69.4 \%)$ & $22(51.2 \%)$ & 0.360 \\
\hline
\end{tabular}

$W$ women, $M$ men

a) Major postoperative complications within eight weeks after surgery 
Table 5 Predictors of overall survival, stratified (on disease-categories) analysis

\begin{tabular}{|c|c|c|c|c|c|c|}
\hline \multicolumn{7}{|c|}{ Risk factors, complications and overall survival } \\
\hline & \multicolumn{3}{|c|}{ Unadjusted } & \multicolumn{3}{|c|}{ Multivariable adjusted } \\
\hline & $\mathrm{HR}$ & $95 \% \mathrm{Cl}$ & P-value & $\mathrm{HR}$ & $95 \% \mathrm{Cl}$ & $P$-value \\
\hline Age $>65$ years & 1.29 & $0.99-1.68$ & 0.058 & 1.21 & $0.92-1.58$ & 0.173 \\
\hline Male gender & 1.11 & $0.85-1.45$ & 0.456 & 1.02 & $0.78-1.34$ & 0.873 \\
\hline Weight loss $>5 \%$ & 1.48 & $1.12-1.94$ & 0.005 & 1.38 & $1.04-1.83$ & 0.023 \\
\hline Serum-albumin $<35 \mathrm{~g} / \mathrm{l}$ & 1.80 & $1.30-2.49$ & $<0.001$ & 1.52 & $1.09-2.14$ & 0.014 \\
\hline Complications & 1.58 & $1.21-2.06$ & 0.001 & 1.51 & $1.15-1.98$ & 0.003 \\
\hline \multicolumn{7}{|c|}{ Complications and overall survival excluding patients alive $<90$ days ${ }^{a}$} \\
\hline Complications & 1.30 & $0.97-1.75$ & 0.075 & 1.25 & 0.93-1.69 & 0.133 \\
\hline \multicolumn{7}{|c|}{ Sarcopenia and overall survival ${ }^{b}$} \\
\hline Sarcopenia & 0.66 & $0.45-0.98$ & 0.037 & 0.69 & $0.46-1.03$ & 0.066 \\
\hline \multicolumn{7}{|c|}{ Weight loss, serum-albumin and tissue indices, analyzed as continuous variables, and overall survival ${ }^{c}$} \\
\hline Weight loss (\%) & 1.05 & $1.02-1.08$ & 0.002 & 1.05 & $1.01-1.09$ & 0.010 \\
\hline Serum-albumin (g/l) & 0.97 & $0.94-0.99$ & 0.018 & 0.96 & $0.93-0.99$ & 0.020 \\
\hline L3 SMI $\left(\mathrm{cm}^{2} / \mathrm{m}^{2}\right)$ & 1.02 & $0.99-1.05$ & 0.301 & 1.00 & $0.96-1.04$ & 0.914 \\
\hline L3 VAT $\left(\mathrm{cm}^{2} / \mathrm{m}^{2}\right)$ & 1.00 & $1.00-1.01$ & 0.491 & 1.00 & $0.99-1.01$ & 0.426 \\
\hline L3 SAT $\left(\mathrm{cm}^{2} / \mathrm{m}^{2}\right)$ & 1.00 & $0.99-1.01$ & 0.657 & 1.00 & $0.99-1.01$ & 0.897 \\
\hline
\end{tabular}

a) Major postoperative complications within eight weeks after surgery. Adjusted for age $>65$ years, gender, weight loss $>5 \%$ and serum-albumin $<35$ g/l in the multivariable adjusted analysis

b) Patients with available preoperative CT images ( $n=157)$. L3 SMl $<41 \mathrm{~cm}^{2} / \mathrm{m}^{2}$ for women. L3 SMl $<43 \mathrm{~cm}^{2} / \mathrm{m}^{2}$ for men with BMl $<25 \mathrm{~kg} / \mathrm{m}^{2}$ and L3 SMI $<53 \mathrm{~cm} / \mathrm{m}^{2}$ for men with $\mathrm{BMI} \geq 25 \mathrm{~kg} / \mathrm{m}^{2}$. Adjusted for age $>65$ years, gender, weight loss $>5 \%$ and serum-albumin $<35 \mathrm{~g} / \mathrm{l}$ in the multivariable adjusted analysis

c) Patients with available preoperative CT images $(n=157)$. Age $>65$ years and gender is also included in the multivariable adjusted analysis

We used the cut-offs suggested by Martin et al. and found a significant association between sarcopenia and improved overall survival in the unadjusted analysis, but not in the multivariable adjusted analysis. We find it unlikely that sarcopenic patients have improved overall survival following major upper abdominal surgery. There was no significant association when L3 Skeletal muscle index was analyzed as a continuous variable, nor was there any difference in five-year mortality between the different quartile categories of L3 SMI index. We suggest that this exemplifies the known hazards of using a dichotomous variable in a heterogeneous cohort of patients [30]. We have indeed presented preoperative weight loss and serum-albumin as dichotomous variables, but the association between these variables and overall survival was confirmed when analyzed as continuous variables. No cut-off values were applied when analyzing L3 VAT and L3 SAT indices. There was no association between these continuous variables and survival and to our knowledge, no cutoff values are established.

The lack of association between the tissue indices analyzed in our study and outcome might indicate that these indices do not necessarily mirror a disease-related catabolic process. Instead, they may provide only a spot measurement of body composition with a large normal variance. In a study with a relatively small number of patients, Awad et al. reported a significant loss of skeletal muscle tissue in a esophagogastric cancer patients who received neoadjuvant chemotherapy, but no association between such tissue loss and clinical outcomes [31]. The potential association between ongoing loss of skeletal muscle tissue, i.e. a catabolic process, and outcomes should be explored further.

An association between sarcopenia and survival in specific patient categories, like primary liver cancer patients or sarcopenic-obese patients has been reported $[7,9,29]$. Tissue indices might be particularly important in these categories, but the number of patients with these characteristics in our study was too small for any meaningful analysis.

The association between sarcopenia and survival may not be equal in all diseases or even in different stages of the same disease. Del et al. reported more complete pathological response and longer progression free survival in sarcopenic, compared to non-sarcopenic, patients with operable breast cancer who received neoadjuvant chemotherapy [32]. Prado et al. reported increased chemotherapy toxicity and shorter time to tumor progression in sarcopenic, compared, to nonsarcopenic patients with metastatic breast cancer who received Capecitabine [11]. Body composition indices might be important when patients receive chemotherapeutic agents that are unevenly distributed in the different body compartments. The reasons behind a low skeletal muscle index might also differ depending on cancer stage and development. 
Major postoperative complications have been associated with reduced survival for patients surgically treated for malignant or non-malignant diseases [14-19]. Nonfatal complications (excluding patients who die within 30 days after surgery) has also been linked to reduced survival [14]. This has led to speculations concerning an immune modulating effect of complications which might make the patient more susceptible to cancer recurrence $[14,15]$. We extended the definition of fatal complications to death within 90 days and found no association between non-fatal complications and reduced survival. Major postoperative complications may preclude or delay administration of adjuvant chemotherapy [17]. Both the administration and the benefit of adjuvant chemotherapy is diverse in heterogenic upper GI and HPB patient groups like ours and this may also explain why we could not find any association between complications and survival.

Our cohort consisted of patients enrolled in a national multicenter clinical trial [20]. This trial investigated the safety of food at will after all kinds of major upper abdominal surgery [20]. Using this cohort, without further selection of patients, gave us the opportunity to investigate both old and novel indicators of poor prognosis in a clinical setting and to do so prospectively with long observation time.

Our study has several weaknesses: We lacked information about cancer-stage, and the number of patients with available CT-images of sufficient quality was relatively small. The patients in our cohort have not been controlled in a homogeneous follow-up program, so cause of death and disease-specific survival would be unreliable. Despite these weaknesses, our study adds important knowledge: While preoperative weight loss and abnormal serum-albumin were associated with reduced survival independent of disease-categories, the opposite pattern was shown with the body composition indices. Cancer-stage is an important confounder, probably linked to both weight loss and serumalbumin. Exact information about cancer-stage is generally not available in a preoperative setting, which make global indicators, like preoperative weight loss and serum-albumin, important in recognizing advanced disease.

\section{Conclusion}

Our study adds to the core knowledge of preoperative weight loss and abnormal preoperative serum-albumin as important preoperative indicators of poor prognosis. These tools are independent of age, gender, and disease category in upper abdominal surgery. Body composition indices, as defined and utilized in the present study, did not provide additional information of clinical importance. We did not find any evidence of an association between non-fatal complications and longterm survival in major upper abdominal surgery.

\section{Ethical considerations}

Inclusion into the original randomized controlled trial [20], as well as long-term follow-up was approved by the Regional Committee on Research Ethics, Northern Chapter (REK V). All patients provided written consent.

\begin{abstract}
Abbreviations
Gl: Gastrointestinal; HPB: Hepatopancreatobiliary; L3 SMI: Lumbar skeletal muscle index; L3 VAT: Visceral adipose tissue index; L3 SAT: Subcutaneous adipose tissue index; WL: Weight loss.
\end{abstract}

\section{Competing interests}

The authors declare they have no competing interests.

\section{Authors' contributions}

Study conception and design: EKAa, KCF, AR, KL. Data acquisition: EKAa, GT, AH, JAS, KL. Data analysis: EKAa, NJ, KL. Data interpretation and manuscript preparation, editing and final approval: All authors.

\section{Acknowledgements}

The authors' thanks consultant surgeon, A. Bernstein, for data collection from Sørlandet hospital Arendal and Prof. of Medical Statistics, T. Wilsgaard, The Arctic University of Norway, for his assistance.

\section{Author details}

'Department of GI and HPB Surgery, University Hospital of Northern Norway, Tromsø 9038, Breivika, Norway. ${ }^{2}$ Institute of Clinical Medicine, University of Tromsø - The Arctic University of Norway, Tromsø, Norway. ${ }^{3}$ Department of Gastrointestinal Surgery, St. Olavs Hospital - Trondheim University Hospital, Trondheim, Norway. ${ }^{4}$ Clinical Surgery, University of Edinburgh, Royal Infirmary of Edinburgh, Edinburgh, UK. ${ }^{5}$ Department of Abdominal and Emergency Surgery, Haukeland University Hospital, Bergen, Norway. ${ }^{6}$ Department of Gastrointestinal Surgery, Stavanger University Hospital, Stavanger, Norway. 'Department of Clinical Medicine, University of Bergen, Bergen, Norway.

Received: 20 February 2015 Accepted: 26 June 2015

Published online: 07 July 2015

\section{References}

1. Parekh NR, Steiger E. Percentage of weight loss as a predictor of surgical risk: from the time of Hiram Studley to today. Nutr Clin Pract. 2004;19:471-6.

2. Daley J, Khuri SF, Henderson W, Hur K, Gibbs JO, Barbour G, et al. Risk adjustment of the postoperative morbidity rate for the comparative assessment of the quality of surgical care: results of the National Veterans Affairs Surgical Risk Study. J Am Coll Surg. 1997;185:328-40.

3. Khuri SF, Daley J, Henderson W, Hur K, Gibbs JO, Barbour G, et al. Risk adjustment of the postoperative mortality rate for the comparative assessment of the quality of surgical care: results of the National Veterans Affairs Surgical Risk Study. J Am Coll Surg. 1997;185:315-27.

4. Studley HO. Percentage of weight loss: a basic indicator of surgical risk in patients with chronic peptic ulcer. 1936. Nutr Hosp. 2001;16:141-3.

5. Dewys WD, Begg C, Lavin PT, Band PR, Bennett JM, Bertino JR, et al. Prognostic effect of weight loss prior to chemotherapy in cancer patients. Eastern Cooperative Oncology Group. Am J Med. 1980;69:491-7.

6. Fearon K, Strasser F, Anker SD, Bosaeus I, Bruera E, Fainsinger RL, et al. Definition and classification of cancer cachexia: an international consensus. Lancet Oncol. 2011;12:489-95

7. Harimoto N, Shirabe K, Yamashita Yl, Ikegami T, Yoshizumi T, Soejima Y, et al. Sarcopenia as a predictor of prognosis in patients following hepatectomy for hepatocellular carcinoma. Br J Surg. 2013;100:1523-30.

8. van Vledder MG, Levolger S, Ayez N, Verhoef C, Tran TC, ljzermans JN. Body composition and outcome in patients undergoing resection of colorectal liver metastases. Br J Surg. 2012;99:550-7. 
9. Itoh S, Shirabe K, Matsumoto Y, Yoshiya S, Muto J, Harimoto N, et al. Effect of Body Composition on Outcomes after Hepatic Resection for Hepatocellular Carcinoma. Ann Surg Oncol. 2014;21(9):3063-8.

10. Du Y, Karvellas CJ, Baracos V, Williams DC, Khadaroo RG. Sarcopenia is a predictor of outcomes in very elderly patients undergoing emergency surgery. Surgery. 2014;156:521-7.

11. Prado CM, Baracos VE, McCargar LJ, Reiman T, Mourtzakis M, Tonkin K, et a Sarcopenia as a determinant of chemotherapy toxicity and time to tumor progression in metastatic breast cancer patients receiving capecitabine treatment. Clin Cancer Res. 2009:15:2920-6.

12. Sabel MS, Terjimanian M, Conlon AS, Griffith KA, Morris AM, Mulholland MW et al. Analytic morphometric assessment of patients undergoing colectomy for colon cancer. J Surg Oncol. 2013;108:169-75.

13. Miller BS, Ignatoski KM, Daignault S, Lindland C, Doherty M, Gauger PG, et al. Worsening central sarcopenia and increasing intra-abdominal fat correlate with decreased survival in patients with adrenocortical carcinoma. World J Surg. 2012;36:1509-16.

14. Khuri SF, Henderson WG, DePalma RG, Mosca C, Healey NA, Kumbhani DJ. Determinants of long-term survival after major surgery and the adverse effect of postoperative complications. Ann Surg. 2005;242:326-41.

15. Mavros MN, de Jong M, Dogeas E, Hyder O, Pawlik TM. Impact of complications on long-term survival after resection of colorectal liver metastases. Br J Surg. 2013:100:711-8.

16. Cho JY, Han HS, Yoon YS, Hwang DW, Jung K, Kim YK. Postoperative complications influence prognosis and recurrence patterns in periampullary cancer. World J Surg. 2013;37:2234-41.

17. Krarup PM, Nordholm-Carstensen A, Jorgensen LN, Harling H. Anastomotic Leak Increases Distant Recurrence and Long-Term Mortality After Curative Resection for Colonic Cancer: A Nationwide Cohort Study. Ann Surg. 2013;259(5):930-8.

18. Kubota T, Hiki N, Sano T, Nomura S, Nunobe S, Kumagai K, et al. Prognostic Significance of Complications after Curative Surgery for Gastric Cancer. Ann Surg Oncol. 2013;21(3):891-8.

19. Pucher PH, Aggarwal R, Qurashi M, Darzi A. Meta-analysis of the effect of postoperative in-hospital morbidity on long-term patient survival. $\mathrm{Br} J$ Surg. 2014;101:1499-508.

20. Lassen K, Kjaeve J, Fetveit T, Trano G, Sigurdsson HK, Horn A, et al. Allowing normal food at will after major upper gastrointestinal surgery does not increase morbidity: a randomized multicenter trial. Ann Surg. 2008;247:721-9.

21. Antoun S, Rey A, Bachmann P. Malnutrition, inflammation: which parameter is interesting to detect in planned oncologic surgery? World J Surg. 2009:33:2728-9.

22. Eknoyan G. Adolphe Quetelet (1796-1874)-the average man and indices of obesity. Nephrol Dial Transplant. 2008;23:47-51.

23. Mitsiopoulos N, Baumgartner RN, Heymsfield SB, Lyons W, Gallagher D, Ross R. Cadaver validation of skeletal muscle measurement by magnetic resonance imaging and computerized tomography. J Appl Physiol (1985). 1998;85:115-22.

24. Miller KD, Jones E, Yanovski JA, Shankar R, Feuerstein I, Falloon J. Visceral abdominal-fat accumulation associated with use of indinavir. Lancet. 1998;351:871-5.

25. Shen W, Punyanitya M, Wang Z, Gallagher D, St-Onge MP, Albu J, et al. Total body skeletal muscle and adipose tissue volumes: estimation from a single abdominal cross-sectional image. J Appl Physiol (1985). 2004;97:2333-8.

26. Martin L, Birdsell L, MacDonald N, Reiman T, Clandinin MT, McCargar LJ, et al. Cancer cachexia in the age of obesity: skeletal muscle depletion is a powerful prognostic factor, independent of body mass index. J Clin Oncol. 2013:20(31):1539-47.

27. Mourtzakis M, Prado CM, Lieffers JR, Reiman T, McCargar $U$, Baracos VE. A practical and precise approach to quantification of body composition in cancer patients using computed tomography images acquired during routine care. Appl Physiol Nutr Metab. 2008;33:997-1006.

28. Englesbe MJ, Patel SP, He K, Lynch RJ, Schaubel DE, Harbaugh C, et al. Sarcopenia and mortality after liver transplantation. J Am Coll Surg. 2010;211:271-8.
29. Prado CM, Lieffers JR, McCargar LJ, Reiman T, Sawyer MB, Martin L, et al. Prevalence and clinical implications of sarcopenic obesity in patients with solid tumours of the respiratory and gastrointestinal tracts: a populationbased study. Lancet Oncol. 2008;9:629-35.

30. Altman DG, Royston P. The cost of dichotomising continuous variables. BMJ. 2006;332:1080.

31. Awad S, Tan BH, Cui H, Bhalla A, Fearon KC, Parsons SL, et al. Marked changes in body composition following neoadjuvant chemotherapy for oesophagogastric cancer. Clin Nutr. 2012;31:74-7.

32. Del FE, Parsons H, Warneke CL, Pulivarthi K, Litton JK, Dev R, et al. The relationship between body composition and response to neoadjuvant chemotherapy in women with operable breast cancer. Oncologist. 2012;17:1240-5.

\section{Submit your next manuscript to BioMed Central and take full advantage of:}

- Convenient online submission

- Thorough peer review

- No space constraints or color figure charges

- Immediate publication on acceptance

- Inclusion in PubMed, CAS, Scopus and Google Scholar

- Research which is freely available for redistribution 